\title{
THE RELATIVE MERITS OF ENCEPHALOGRAPHY AND VENTRICULOGRAPHY FOR THE INVESTIGATION OF INTRACRANIAL TUMOURS
}

\author{
BY \\ GÖSTA NORLÉN AND INGMAR WICKBOM
}

From the Departments of Neurosurgery and Radiology, Sahlgrens Hospital, Göteborg, Sweden

The view was formerly held, and still is in many centres, that encephalography should not be used in cases where the intracranial pressure is raised or if a posterior fossa tumour is suspected. Several authors prefer ventriculography to encephalography in all cases where the clinical signs and symptoms indicate a brain tumour. The main reason for this seems to be that the risk of coning after the procedure is considered to be high. Using the old technique, which means that a large amount of fluid is drained before gas is injected, this risk must be considerable, especially if there should be a block at the foramen of Magendie, for example.

In recent times, however, a technique, based on the principle that the pressure should be maintained as well as possible (Lindgren, 1949, 1950, 1951, 1954; Robertson, 1941, 1946, and others), has been introduced. The technique, described by Lindgren seems to be the one which is most satisfactory in that respect. According to Lindgren, only a few drops of fluid (enough to make sure that the needle is in the right position) should be allowed to escape before gas is injected. The fluid-gas exchange is performed in fractions of 5 to $10 \mathrm{ml}$., the gas always being injected before the same amount or somewhat less fluid is withdrawn. If the intracranial pressure is raised practically no fluid is allowed to escape, at least not until gas is seen to enter the ventricular system. In this way the risks of coning must be greatly diminished.

It is well known that ventriculography is not free from risks. The pressure conditions may be considerably altered causing herniation. Also the brain puncture itself may cause damage to the brain substance. Zülch, Hirnödem, Hirnschwellung, and Hirndruck (1951) have demonstrated oedema along the track of the needle and calcification can often be seen further along this track (Falk, 1951, 1953). Sometimes the puncture, especially if difficult, may cause more severe damage in the form of haemorrhages and malacia.
When deciding which method of examination should be used, not only the risks involved in the method should be considered but also the information that can be gained from it. Provided the C.S.F. pathways are free and ventricular filling can be obtained at encephalography, this method allows a more complete examination than does ventriculography, as the cisterns can also be studied. This is of special value in cases with basal extracerebral tumours. These tumours as a rule can be outlined by gas in the cisterns (Figs. 1, 2, and 3). Extracerebral tumours which are too small to cause any deformity of the ventricular system cannot be demonstrated at all by means of ventriculography. Falk also points out that gas sometimes passes more easily from the third ventricle through the foramen of Monro than in the opposite direction. Thus, for example, in cases where the anterior part of the third ventricle is compressed by a large suprasellar tumour it may be impossible to fill the third ventricle at ventriculography. At encephalography it should always be possible to make a correct diagnosis in tumours of this kind.

Using a correct technique an adequate filling of the ventricular system can be obtained in more than $95 \%$ of cases, provided the pathways are not obliterated. The aqueduct and fourth ventricle can be studied more easily and accurately at encephalography in the sitting position, when gas passes into the ventricles, than at ventriculography. At the latter examination pictures have to be taken when gas passes from the ventricular system into the cisterna magna. The gas may then disappear before the pictures are taken. If, on the other hand, the C.S.F. pathways are obliterated, ventriculography is necessary for examination of the ventricular system. Even in these cases, however, encephalography may provide valuable information. If the tumour is outlined by gas in the cisterns examination of the ventricles is as a rule not necessary (Fig 3).

In cases where the block is situated in the aqueduct 


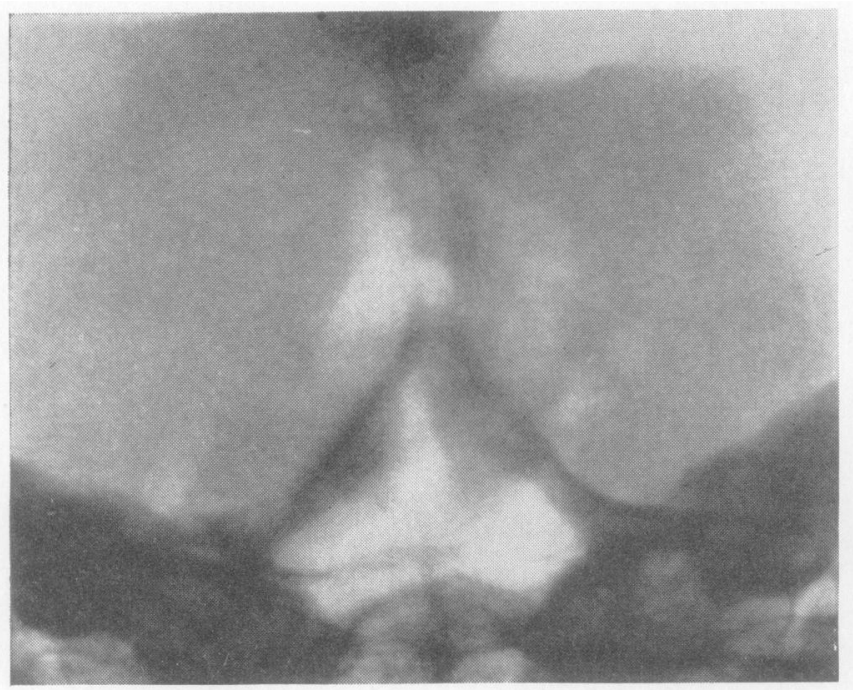

FIG 1-Acoustic neurinoma on the left side. Cerebellopontine cistern is displaced medially and outlines the tumour. Small indentation in the fourth ventricle from the left and below. Ventricular system otherwise normal.
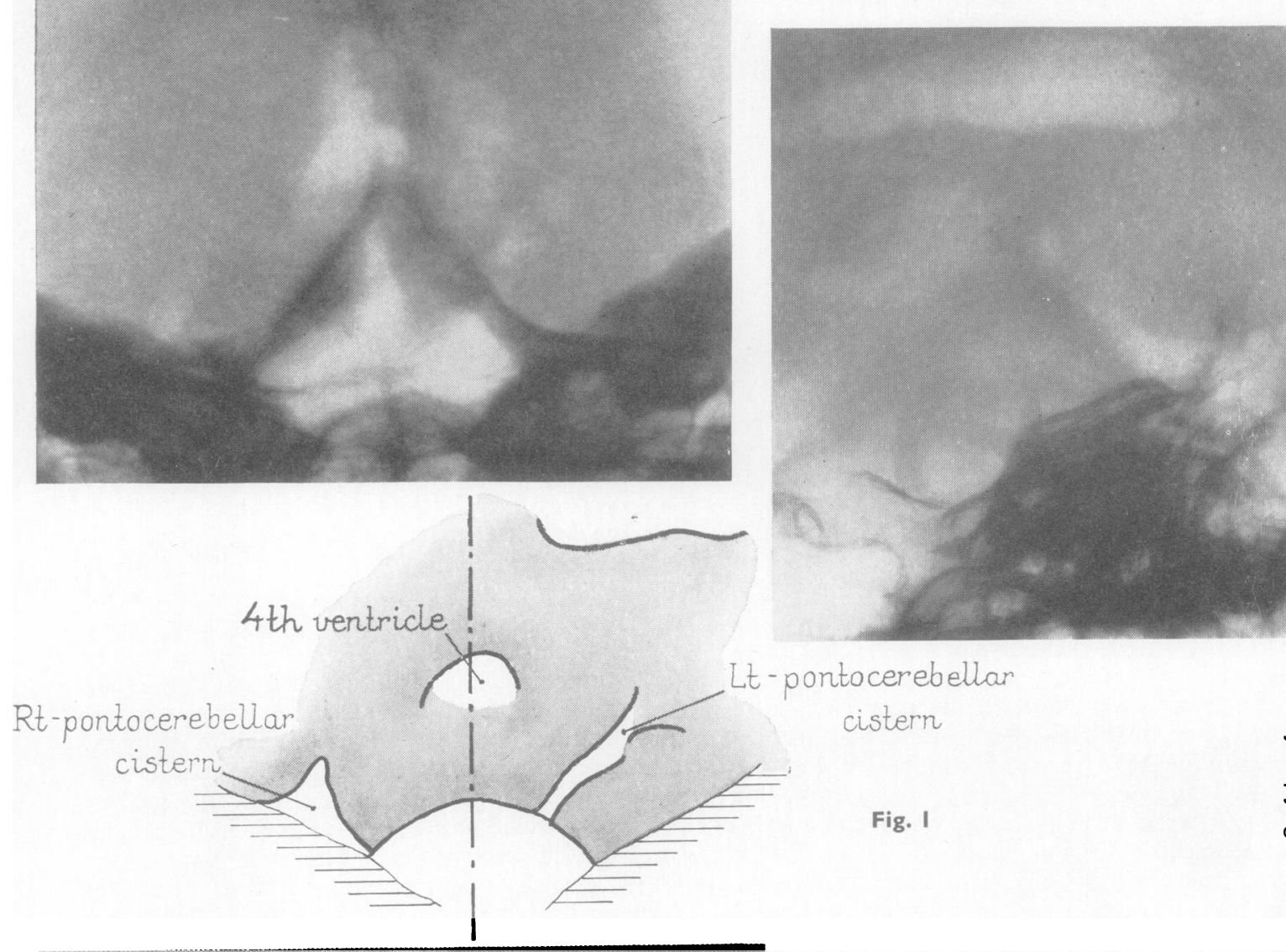

pontocerebellar

cistern

Fig. I

FIG. 2.-Meningioma from the sphenoidal plane outlined by cisternal gas. Slight bulging from below in the anterio horns.
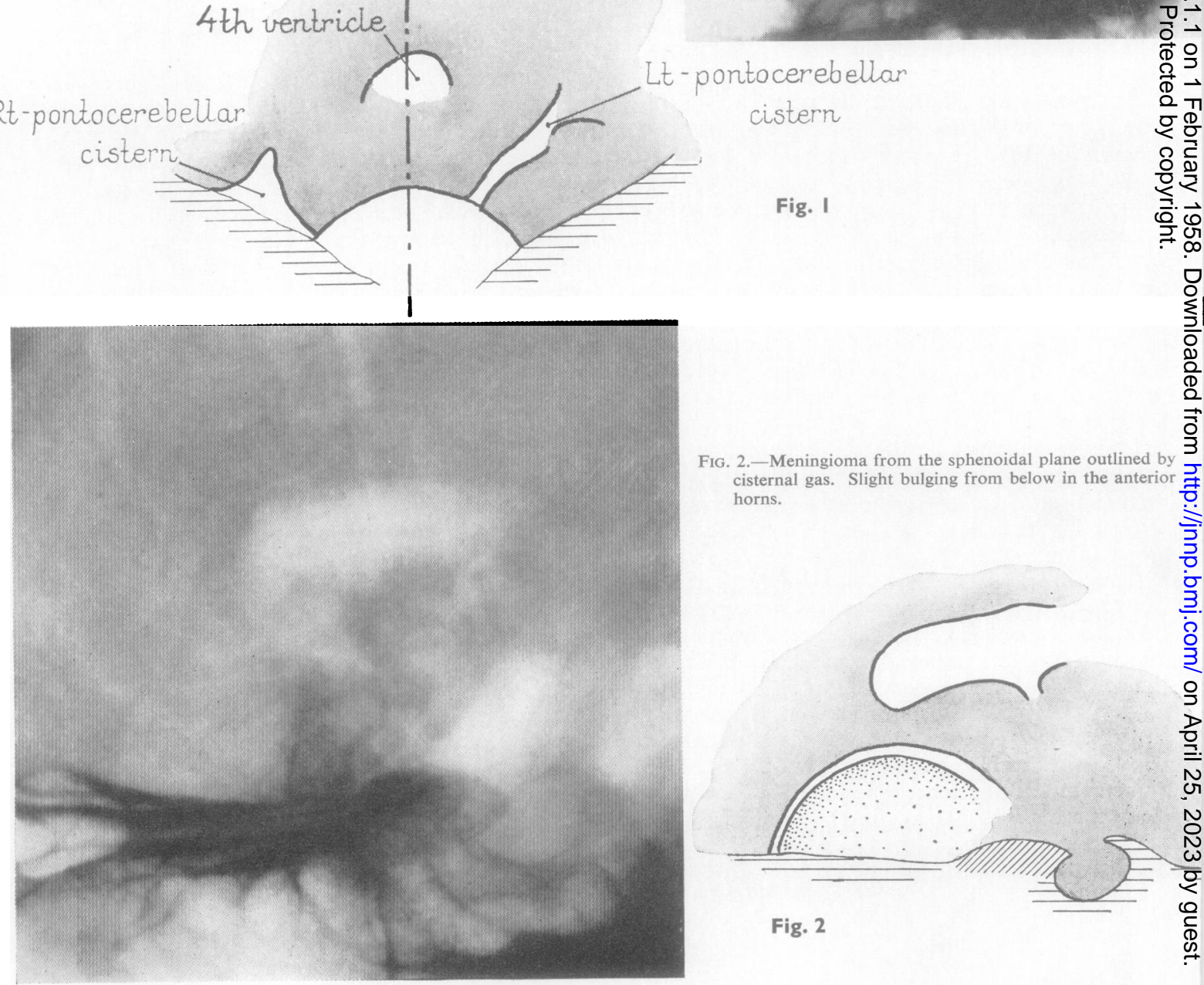

Fig. 2 
FIG. 3.-Large meningioma on the right side mainly arising from the tentorium. The tumour is outlined by cisternal gas and can be exactly localized in spite of the fact that no ventricular filling is obtained.
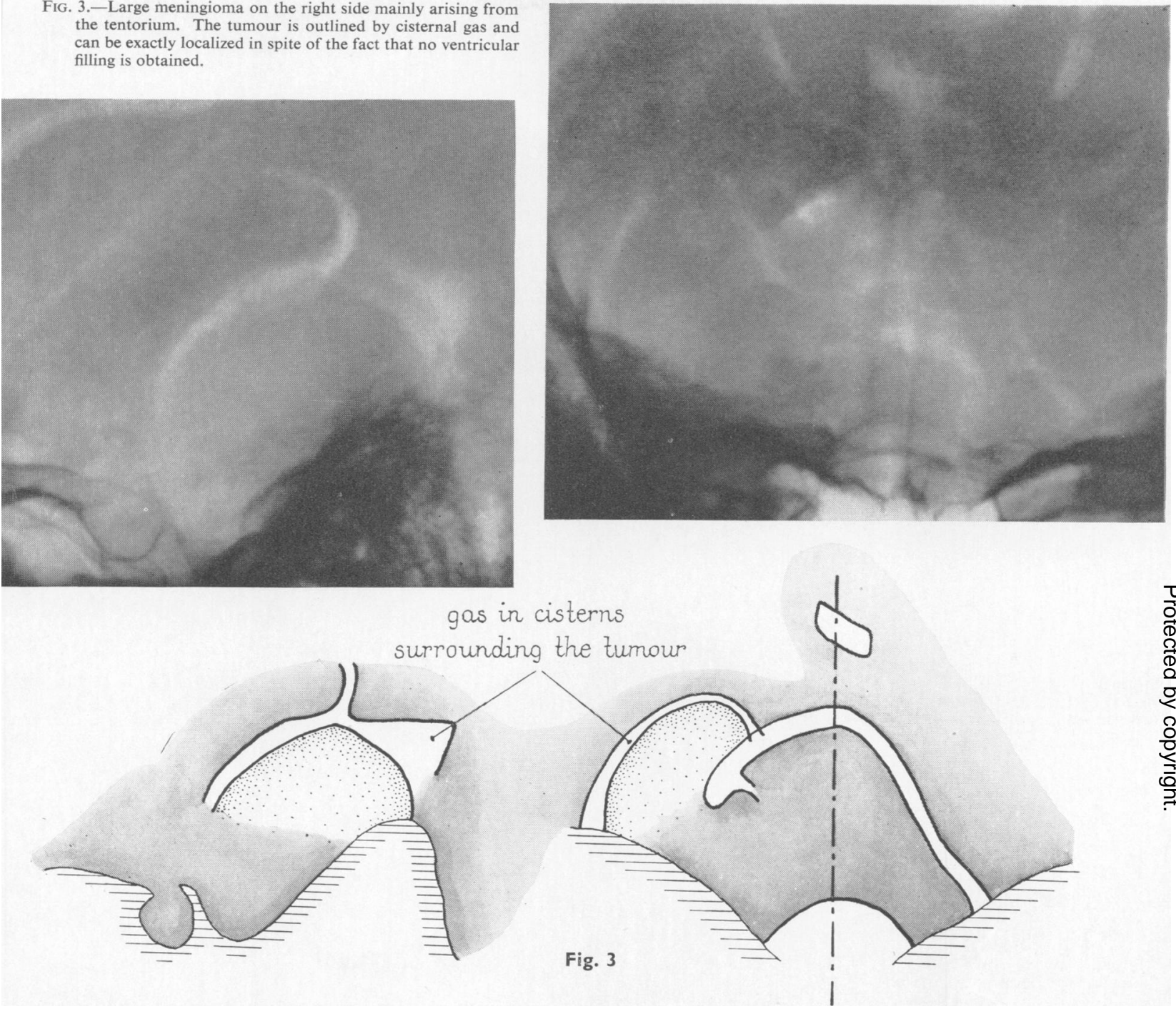

or in the third ventricle, the part of the ventricular system below the block may be filled at encephalography, thus allowing a more accurate diagnosis to be made (Figs. 4 and 5). Herniation of the tonsils can be directly seen at encephalography and tentorial herniations also may cause characteristic changes in the cisterns. If the vallecula is filled with air and is seen to be displaced to one side or the other, this indicates that there is an expanding process in the contralateral part of the posterior fossa (Fig. 6).

In recent years several cases and series of cases have been reported where this modern technique has been used also in posterior fossa tumours and in cases where the intracranial pressure is raised
(Lindgren, 1951 ; Falk, 1953; Ruggiero, David, and Talairach, 1955; David, Ruggiero, and Talairach, 1954; Ruggiero, 1956; Robertson, 1941, 1946; Dressler and Albrecht, 1956; Sheldon, Wickbom, and Pennybacker, 1953; Wickbom and Sheldon, 1953) among many others. Falk, in his series of 195 tumour cases (including 37 tumours in the posterior fossa) examined by encephalography, reported no ventricular filling in 24 cases (eight supraand 16 infratentorial tumours). In six cases attacks of herniation occurred after the procedure. In only one of them, a pontine glioma for which ventriculography was also performed, was the result fatal. Ruggiero et al. (1955) reported four accidents in 40 cases of brain tumour where encephalography 


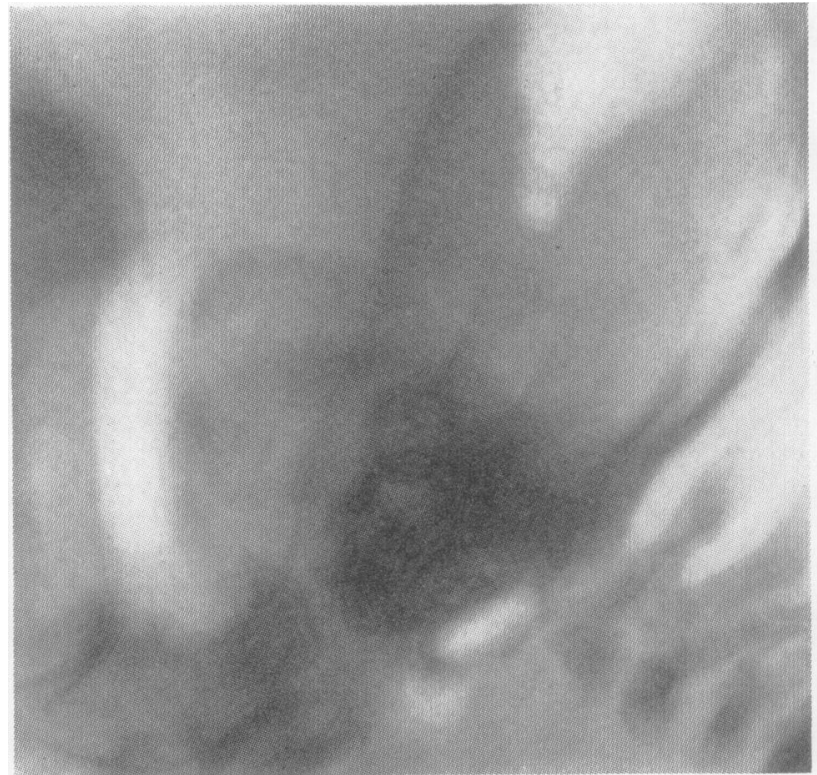

$A$

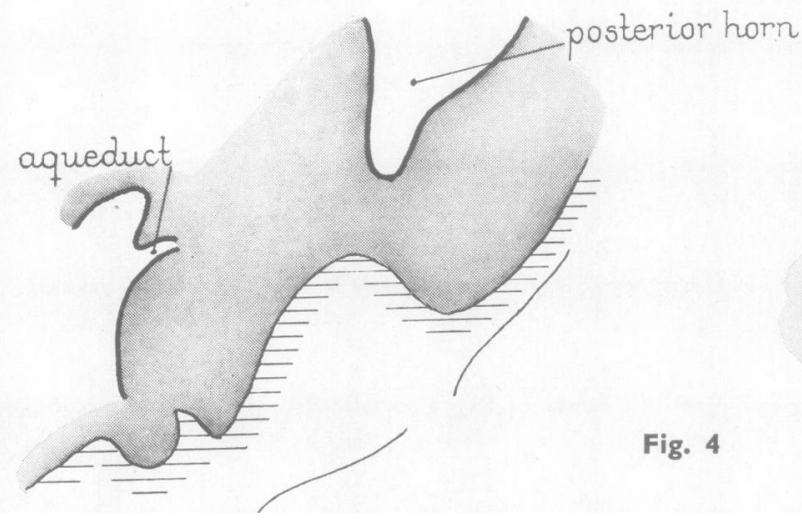

FIG. 4.-Stenosis of the aqueduct. Upper part of the aqueduct is filled at ventriculography $(A)$. Fourth ventricle and lower part of the aqueduct is filled at encephalography $(B)$.

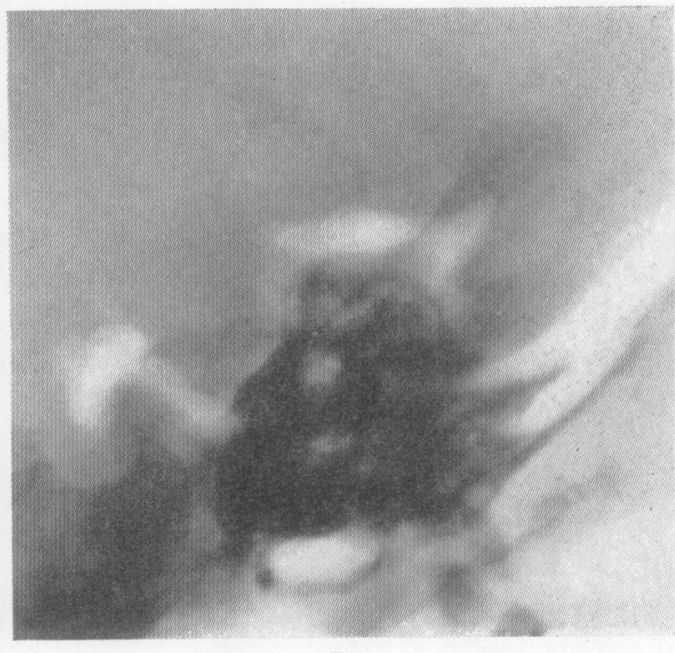

B

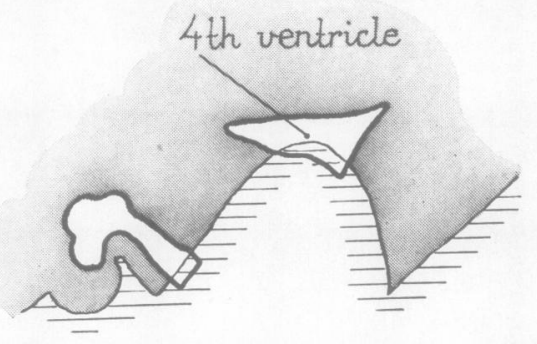

was performed and in four out of 23 cases where ventriculography was used. One of the former and three of the latter were fatal. Dressler and Albrecht (1956) reported deterioration of the patient after encephalography in two cases $(1.2 \%)$ of supratentorial and in three cases $(11 \%)$ of posterior fossa tumour. The corresponding figures for ventriculography were $21(16 \%)$ and eight cases $(13 \%)$ respectively. Falk, as well as Ruggiero et al., used the lumbar route and Dressler and Albrecht cisternal puncture for the insufflation of gas. The motive for using cisternal puncture should be that in this way cases with herniation of the tonsils will be automatically excluded. Dressler and Albrecht are of the opinion that in these cases no ventricular filling can be obtained at encephalography. This is not always true (Fig. 6) and, furthermore, important information may be gained from an encephalographic study even if no ventricular filling is obtained (Figs. 7 and 3).

Judging from these reports it seems as if encephalography performed in this way should involve no more risks than does ventriculography. This is also in accordance with our own experience which dates from the time when we worked at the Serafimer Hospital in Stockholm. In the reports hitherto published the material seems to be in some measure selected. Thus ventriculography has been performed in some of the cases without a preceding attempt to fill the ventricles by means of encephalography. Dressler and Albrecht state that in their cases encephalography was always performed before 
Fig. 5.-Colloid cyst of the foramen of Monro.

$A$. Ventriculography: upper part of the cyst is visualized.

$B$. Encephalography: lower part of the cyst is outlined by gas

in the posterior part of the third ventricle.

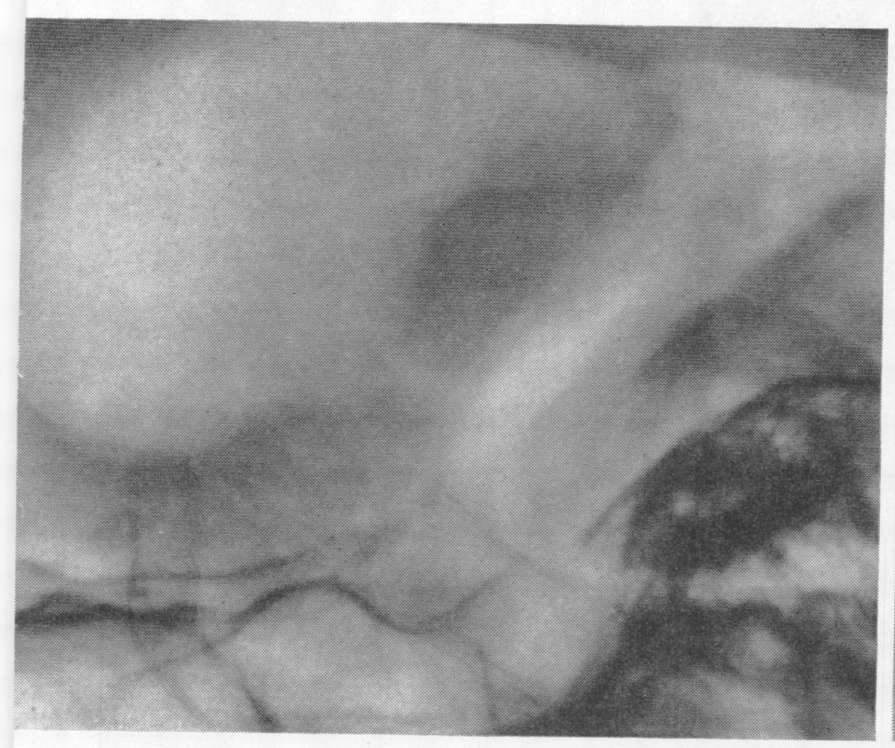

A

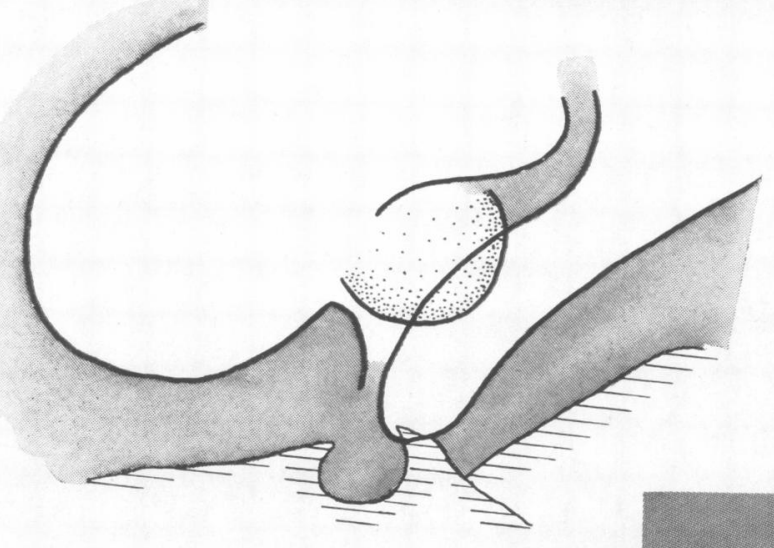

Fig. 5

Fig. 6.-Meningioma over the left cerebellar hemisphere. Gas enters the ventricular system in spite of herniated tonsils (seen on the picture). Marked kink of the aqueduct.

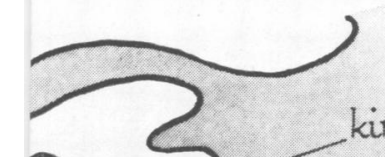

kinked aqueduct
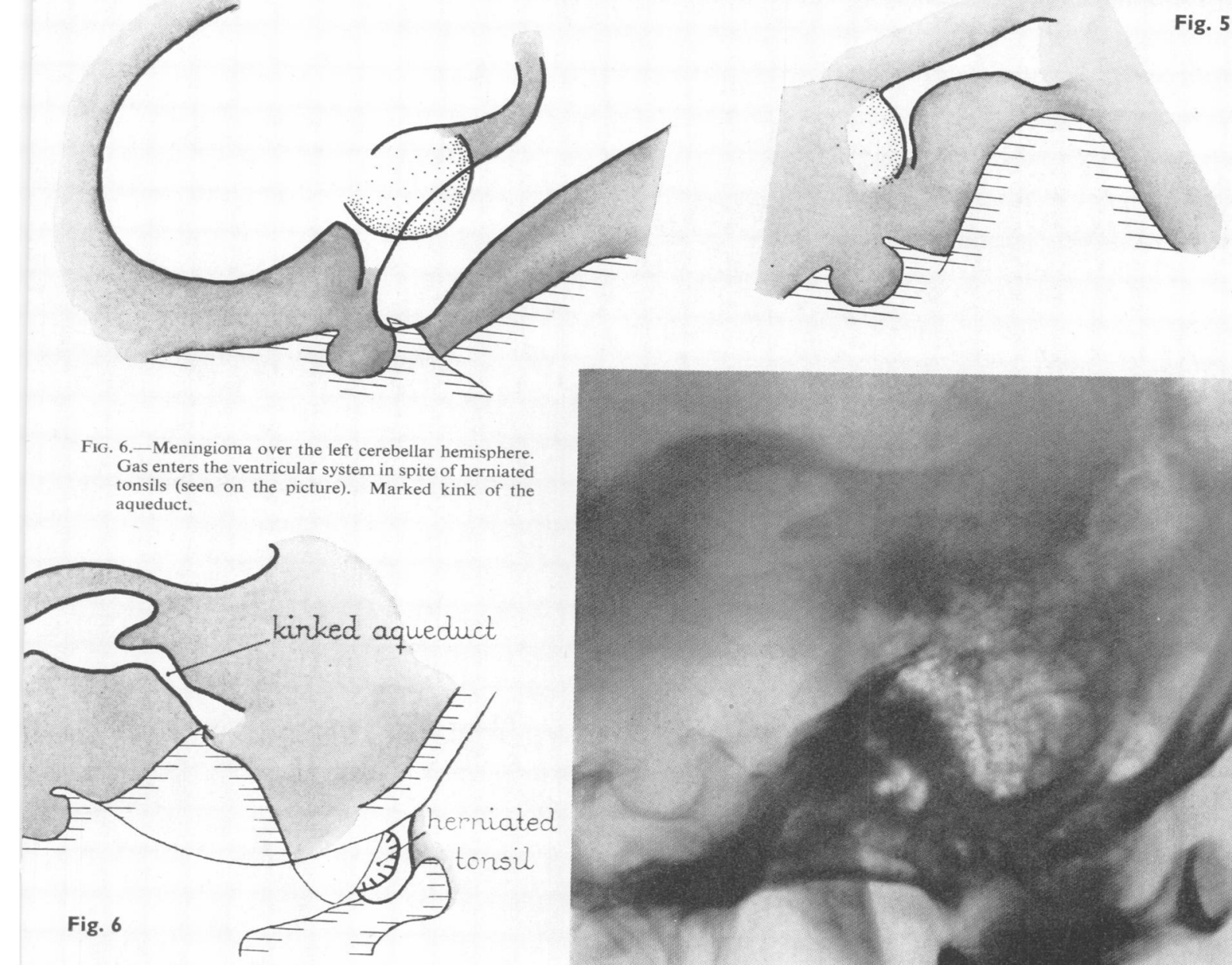


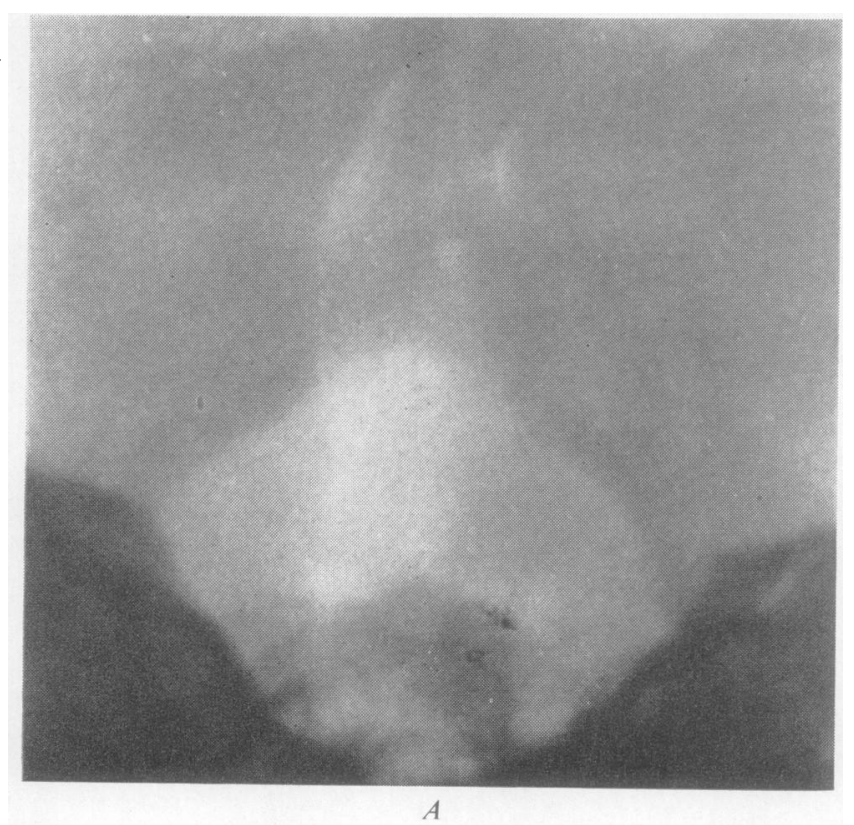

FIG. 7.-Tumour in the left cerebellar hemisphere.

A. Encephalography: gas is seen in the vallecula, which is displaced to the right, indicating a tumour to the left in the posterior fossa.

$B-C$. Ventriculography: marked kink of the aqueduct, indicating a tumour in the dorsal part of the posterior fossa but no definite shift.
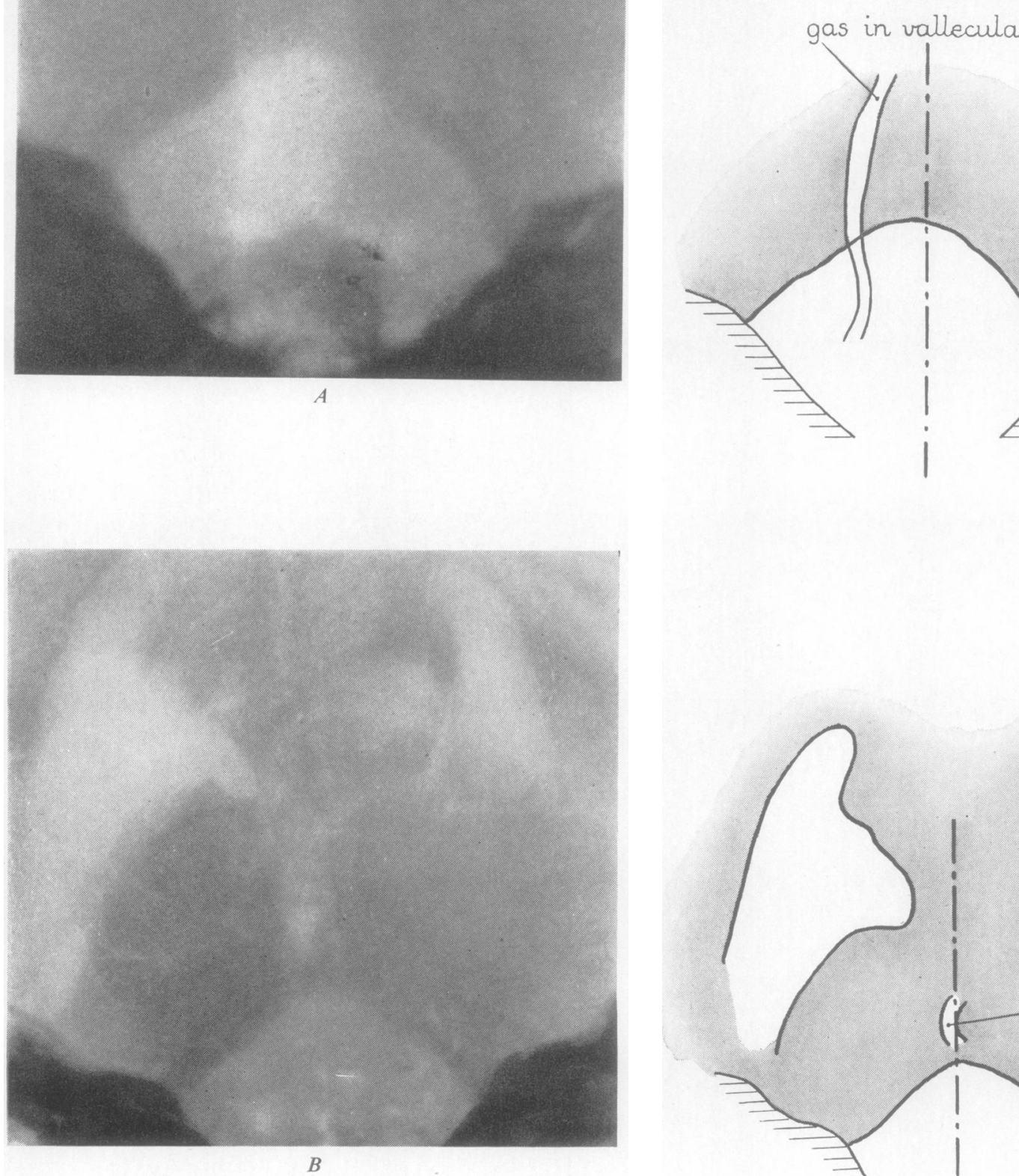

Fig 7

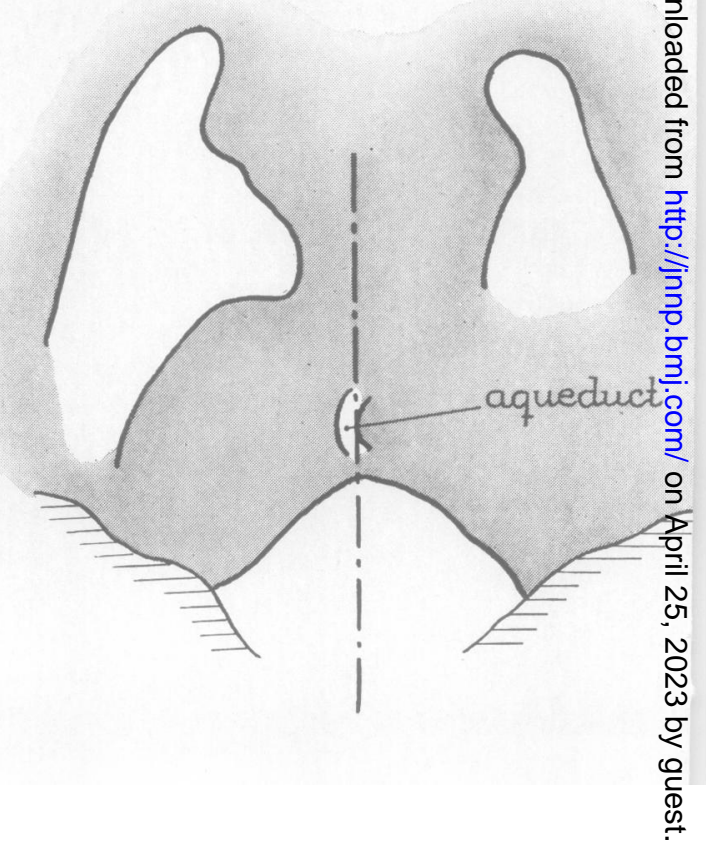



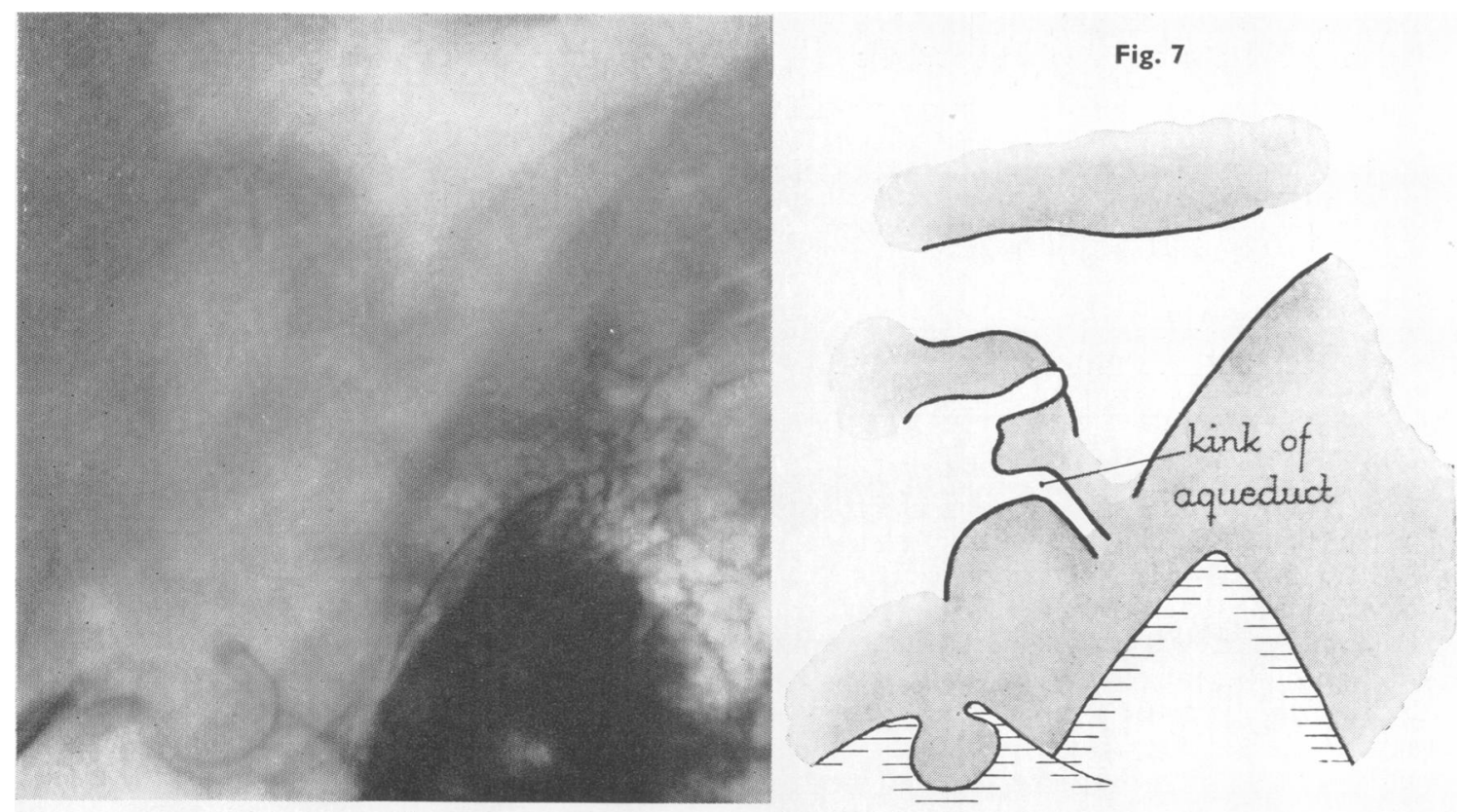

ventriculography. In their material, however, encephalography was performed in 27 cases of infraand in 166 cases of supratentorial tumour. The corresponding figures for ventriculography were 61 and 128 cases respectively. These figures seem to indicate either that encephalography failed to give an accurate diagnosis in a much higher percentage of cases than in our material, or, that in fact only ventriculography had been performed in some of the cases. One explanation of the comparatively high figures for ventriculographies in their material may be that no fluid was obtained at cisternal puncture in several cases. They give no figures as to the diagnostic value of the encephalographic examination.

To form a true opinion of the risks involved and the informative value of the methods, it seems necessary to have a material which is not selected, i.e., which is uniformly treated. From such a material it could be expected that more definite conclusions could be drawn. In that way it might perhaps also be possible to select a certain group of tumours where encephalography is less likely to give enough information and make ventriculography the investigation of choice.

In order to obtain such a series the following principles have been followed ever since the neurosurgical department at Sahlgrens Hospital was started in May, 1953. In all cases where an air study is indicated an attempt is first made to fill the ventricles by the lumbar route. If this fails and if the appearance of the cisterns does not permit of an accurate diagnosis, this examination is followed by ventriculography. In cases where there is evidence of increased pressure or signs indicating a herniation, burr holes are made beforehand. In this way encephalography can be followed directly by ventriculography and ventricular puncture can if necessary be performed at once. The examination is performed by the radiologist but the neurosurgeon can be called immediately if complications of any kind should occur.

For encephalography the technique worked out by Lindgren is used. As a rule the lumbar route is used, thus allowing a freer handling of the patient's head and injection of gas even if the cisterna magna is compressed by herniated tonsils. An air study has as a rule been considered indicated if (1) a lesion in one of the cerebral hemispheres is suspected and carotid angiography appears normal or fails to give all information wanted concerning the extent and true nature of the lesion; (2) in cases where the clinical picture indicates the presence of an intracranial lesion but signs from the cerebral hemispheres are lacking ; (3) cases where the clinical signs indicate a lesion in the posterior fossa.

These are only general rules. For example, in some cases of vascular tumour in the posterior fossa a correct diagnosis has been obtained at vertebral angiography and accordingly an air study has not been necessary. 
TABLE I

TYPES OF TUMOUR DIAGNOSED IN THE WHOLE SERIES

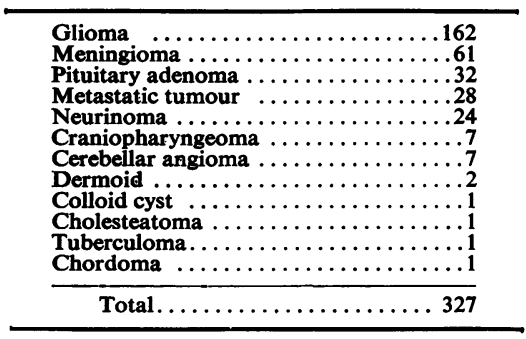

Results in Present Series

Table I illustrates the total tumour material of the clinic in all 327 cases. Two cases of stenosis of the Sylvian aqueduct are grouped together with the gliomas; one of the cases was actually a very small glioma which occluded the aqueduct. In the second case no pathological verification was obtained.

In Table II the material is divided into different groups according to the localization of the tumour. The suprasellar tumours are separated into a special group. The infratentorial tumours are divided into four different groups. One consists of the cerebellopontine angle tumours, neurinomas and meningiomas, in which group the tumours of the clivus, two meningiomas and one chordoma, are included. Another two meningiomas of the posterior fossa were localized to the convexity of the cerebellum involving the cerebellar hemispheres, and accordingly grouped together with the cerebellar tumours. Eight gliomas of the pons constitute one group. The fourth group consists of the two cases of stenosis of the Sylvian aqueduct.

Encephalography was performed in 222 cases, ventriculography in 53, and angiography in 236.

Suprasellar Tumours.-There are 45 suprasellar tumours. In one of them choked disks were present. This patient had a very big chromophobe adenoma growing into the left frontal lobe and angiography indicated the presence of a frontal lobe tumour. The encephalographic examination was incomplete, and only a small amount of air entered the ventricular system. The left frontal horn was displaced indicating a tumour, but the examination did not give
TABLE II

LOCALIZATION OF TUMOURS IN WHOLE SERIES

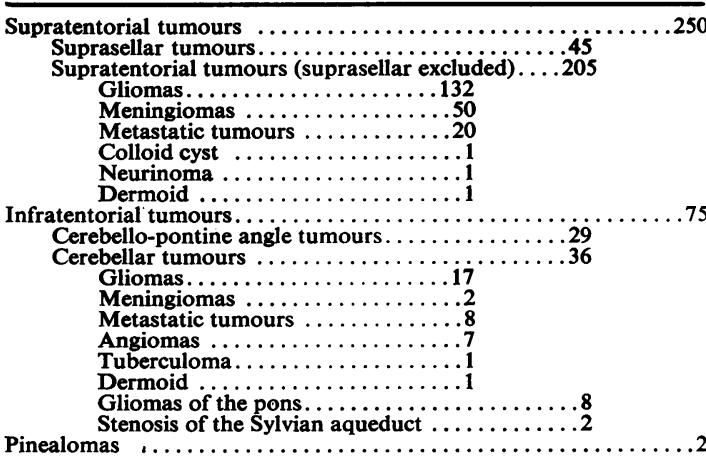

Total...........327

enough information about the exact extent of the tumour. In two cases only no air entered the ventricular system, but in both the suprasellar tumour was outlined by cisternal air.

This group will not be discussed further because pneumography is as a rule not necessary for the localization of the lesion. Encephalography is recom mended if the surgeon wants to visualize the tumour? and obtain more accurate information about itso extensions.

No complications have occurred and ventriculography was not necessary in this group.

Supratentorial Tumours.-The remaining tumours above the tentorium (205 cases), mainly gliomas and meningiomas, are grouped together, 101 of them presenting with choked disks.

Table III demonstrates the result of the air studies. In the table incomplete air filling means that no air or only a small amount of air, for example, only in one side, had entered the ventricular system. In some cases, for example, in some of the suprasellar and the cerebello-pontine angle tumours, the appearance of the cisterns alone permitted a topographical diagnosis. A positive result means that the ventricular system is adequately filled with air permitting a reliable topographical diagnosis. A negative result means that the examination is complete but appears normal or

TABLE III

SUPRATENTORIAL TUMOURS (SUPRASELLAR TUMOURS EXCLUDED)

\begin{tabular}{|c|c|c|c|c|c|c|c|c|c|c|}
\hline \multirow[b]{2}{*}{$\begin{array}{l}\text { Technique } \\
\text { Used }\end{array}$} & \multicolumn{2}{|c|}{ Positive } & \multicolumn{2}{|c|}{ Negative } & \multicolumn{2}{|c|}{ Tumour Suspected } & \multicolumn{2}{|c|}{$\begin{array}{l}\text { Incomplete } \\
\text { Air-filling }\end{array}$} & \multicolumn{2}{|c|}{$\begin{array}{l}\text { Air in Cisterns } \\
\text { Indicating Tumour }\end{array}$} \\
\hline & $\begin{array}{l}\text { Choked } \\
\text { Disks }\end{array}$ & $\begin{array}{l}\text { No } \\
\text { Choked } \\
\text { Disks }\end{array}$ & $\begin{array}{l}\text { Choked } \\
\text { Disks }\end{array}$ & $\begin{array}{l}\text { No } \\
\text { Choked } \\
\text { Disks }\end{array}$ & $\begin{array}{l}\text { Choked } \\
\text { Disks }\end{array}$ & $\begin{array}{l}\text { No } \\
\text { Choked } \\
\text { Disks }\end{array}$ & $\begin{array}{l}\text { Choked } \\
\text { Disks }\end{array}$ & $\begin{array}{l}\text { No } \\
\text { Choked } \\
\text { Disks }\end{array}$ & $\begin{array}{l}\text { Choked } \\
\text { Disks }\end{array}$ & $\begin{array}{c}\text { No } \\
\text { Choked } \\
\text { Disks }\end{array}$ \\
\hline $\begin{array}{l}\text { Encephalography } \\
\text { Ventriculography }\end{array}$ & $\begin{array}{l}24 \\
15\end{array}$ & $\begin{array}{r}57 \\
4\end{array}$ & $\underline{2}$ & 5 & 1 & $\underline{2}$ & 14 & 9 & - & - \\
\hline
\end{tabular}


at least does not permit the diagnosis of an expanding lesion. In some cases deformities of the ventricular system have been too small to permit a definite diagnosis of a tumour and these cases have been classified as "tumour suspect". The ventricular system was incompletely filled with air in 23 cases out of 114 in which encephalography was performed. In only 19 cases had ventriculography to be undertaken. Two of these ventriculograms were not preceded by encephalography. One patient, a 16-month-old girl, had a big glioma in the right ventricle with signs of high pressure. She was in bad condition when referred to the hospital and was operated upon immediately. However, a previous attempt at cisternal puncture had been made and no fluid obtained, thus indicating a herniation of the tonsils. The other patient, a man aged 53 years, was comatose on admission to hospital. A ventriculogram was performed immediately and a left parietal tumour was diagnosed. At operation the same day a malignant glioma was removed.

One of the cases had a colloid cyst at the foramen of Monro and encephalography outlined the posterior part of the tumour in the third ventricle. Only a very small amount of air had entered the lateral ventricles and ventriculography was necessary for complete examination (Fig. 5).

One patient, a case of pterion meningioma with choked disks of 4 diopters, did not tolerate the encephalography. The patient was rather drowsy when the examination was started. After injecting about 5 to $10 \mathrm{ml}$. air she became comatose and a ventricular puncture was done, together with air injection and ventriculography. The patient was operated on the same day with success.

Another case was of a malignant glioma of the left temporal lobe with choked disks of 7 diopters. Air entered the ventricular system at encephalography very slowly and in a small amount and the patient fainted. The examination was therefore abandoned. The patient recovered in some minutes and a subsequent angiogram revealed the malignant glioma.

Cerebello-pontine Angle Tumours.-Of the posterior fossa tumours, one group is composed of the cerebello-pontine angle tumours and tumours of the clivus, 29 cases in all, including 22 neurinomas, two meningiomas of the cerebello-pontine angle, one papilloma in the cerebello-pontine angle, three meningiomas of the clivus, and one chordoma of the clivus. Twelve of these cases presented with choked discs. Encephalography performed in 22 cases was negative in two (Table IV). One of these cases was the papilloma, in which the air study only demonstrated a symmetrical hydrocephalus. The diagnosis was obtained by vertebral angiography. The second case was an acoustic neurinoma with choked disks of 5 diopters. The patient, a 60 -year-old woman, had an atypical history with normal vestibular findings and only slightly diminished hearing on the left side. This was interpreted by the otologists as being caused by local changes after an infection. No changes in the porus could be seen. The case was misinterpreted both from the clinical and radiological points of view. The encephalogram was not tolerated by the patient and ventricular drainage was performed. Three weeks after encephalography the patient was seen by one of us (G. N.) and an operation was performed because the clinical signs and symptoms, in the opinion of the surgeon, definitely indicated a posterior fossa tumour. The operation, however, could not save the life of the patient. In five cases the air study was incomplete in as much as no air entered the ventricular system. In these cases, however, cisternal air outlined the tumour beautifully.

In this group of tumours, as in the suprasellar group, the clinical signs usually, with only few exceptions, were so clear that encephalography was not necessary for the localization of the tumour. If an air study is indicated encephalography should be preferred as it is usually well tolerated and is often more reliable than ventriculography. Ventriculography has not been necessary in this group.

Encephalography was performed in all eight cases of gliomas of the pons (Table V). One of the cases was referred to the hospital in a very advanced state with hemiparesis and difficulties in swallowing, but no choked discs. Encephalography upset this patient but a ventricular tap caused immediate improvement. The patient was not operated upon and died later, death not depending on the en-

TABLE IV

PONTINE ANGLE TUMOURS

\begin{tabular}{|c|c|c|c|c|c|c|c|c|c|c|}
\hline \multirow{2}{*}{$\begin{array}{l}\text { Technique } \\
\text { Used }\end{array}$} & \multicolumn{2}{|c|}{ Positive } & \multicolumn{2}{|c|}{ Negative } & \multirow{2}{*}{$\begin{array}{c}\text { Tumour } \\
\begin{array}{c}\text { Choked } \\
\text { Disks }\end{array}\end{array}$} & \multirow{2}{*}{$\begin{array}{l}\text { Suspected } \\
\begin{array}{c}\text { No } \\
\text { Choked } \\
\text { Disks }\end{array}\end{array}$} & \multicolumn{2}{|c|}{$\begin{array}{l}\text { Incomplete } \\
\text { Air-filling }\end{array}$} & \multicolumn{2}{|c|}{$\begin{array}{l}\text { Air in Cisterns } \\
\text { Indicating Tumour }\end{array}$} \\
\hline & $\begin{array}{c}\text { Choked } \\
\text { Disks }\end{array}$ & $\begin{array}{c}\text { No } \\
\text { Choked } \\
\text { Disks }\end{array}$ & $\begin{array}{l}\text { Choked } \\
\text { Disks }\end{array}$ & $\begin{array}{c}\text { No } \\
\text { Choked } \\
\text { Disks }\end{array}$ & & & $\begin{array}{l}\text { Choked } \\
\text { Disks }\end{array}$ & $\begin{array}{c}\text { No } \\
\text { Choked } \\
\text { Disks }\end{array}$ & $\begin{array}{l}\text { Choked } \\
\text { Disks }\end{array}$ & $\begin{array}{c}\text { No } \\
\text { Choked } \\
\text { Disks }\end{array}$ \\
\hline $\begin{array}{l}\text { Encephalography } \\
\text { Ventriculography }\end{array}$ & $\underline{6}$ & $\underline{9}$ & 2 & - & 二 & - & - & 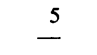 & - & $\underline{5}$ \\
\hline
\end{tabular}


TABLE $\mathrm{V}$

INTRAPONTINE TUMOURS

\begin{tabular}{|c|c|c|c|c|c|c|c|c|c|c|}
\hline \multirow{2}{*}{$\begin{array}{l}\text { Technique } \\
\text { Used }\end{array}$} & \multicolumn{2}{|c|}{ Positive } & \multicolumn{2}{|c|}{ Negative } & \multicolumn{2}{|c|}{ Tumour Suspected } & \multicolumn{2}{|c|}{$\begin{array}{l}\text { Incomplete } \\
\text { Air-filling }\end{array}$} & \multicolumn{2}{|c|}{$\begin{array}{l}\text { Air in Cisterns } \\
\text { Indicating Tumour }\end{array}$} \\
\hline & $\begin{array}{l}\text { Choked } \\
\text { Disks }\end{array}$ & $\begin{array}{l}\text { No } \\
\text { Choked } \\
\text { Disks }\end{array}$ & $\begin{array}{l}\text { Choked } \\
\text { Disks }\end{array}$ & $\begin{array}{l}\text { No } \\
\text { Choked } \\
\text { Disks }\end{array}$ & $\begin{array}{l}\text { Choked } \\
\text { Disks }\end{array}$ & $\begin{array}{c}\text { No } \\
\text { Choked } \\
\text { Disks }\end{array}$ & $\begin{array}{l}\text { Choked } \\
\text { Disks }\end{array}$ & $\begin{array}{c}\text { No } \\
\text { Choked } \\
\text { Disks }\end{array}$ & $\begin{array}{l}\text { Choked } \\
\text { Disks }\end{array}$ & $\begin{array}{c}\text { No } \\
\text { Choked } \\
\text { Disks }\end{array}$ \\
\hline $\begin{array}{l}\text { Encephalography } \\
\text { Ventriculography }\end{array}$ & $\begin{array}{l}1 \\
1\end{array}$ & $\frac{2}{4}$ & 二 & $=$ & 二 & $=$ & 1 & 4 & $=$ & 3 \\
\hline
\end{tabular}

cephalography but on the progress of the inoperable lesion. Ventriculography completed the air study in five cases. Sometimes it can be difficult to say whether the displacement of the aqueduct and the fourth ventricle is caused by an intra- or extrapontine tumour. A study of the air in the basal cisterns is then of great value in the differential diagnosis. Encephalography is therefore more informative in this lesion than is ventriculography. In two cases of stenosis or tumour of the Sylvian aqueduct encephalography and ventriculography supplemented each other, demonstrating the exact extent of the lesion (Fig. 4).

Cerebellar Tumours.-The remaining posterior fossa tumours (36 cases) are grouped together as they are localized to the cerebellar hemispheres, vermis, or the fourth ventricle. In $\mathbf{3 0}$ cases choked disks were present (Table VI).

Thirty-two encephalograms were performed. In four cases no air study was done, vertebral angiography having given an exact diagnosis in two angiomas and in two metastatic tumours.

Encephalography was performed with sufficient air-filling of the ventricular system to permit an accurate diagnosis in three cases.

In another six cases, where the air had not entered the ventricular system, cisternal air localized the tumour to the correct hemisphere. However, ventriculography had to be performed in 26 cases.

Coning of the tonsils was demonstrated in 16 cases, in spite of which the examination was well tolerated. In only one case the clinical symptoms increased after encephalography with attacks of severe headache, but the condition was never alarming and a ventricular tap was not considered necessary. The patient had a metastasic tumour of the cerebellum and on admission presented with severe headache and stiffness of the neck. There was no papilloedema.

Pinealomas.-In the two cases of pinealoma choked disks of 3 diopters were present. In spite of the localization of the tumour and the increased pressure, encephalography could be performed with success and without complication in one of the cases. In the other case encephalography was not tolerated and the examination had to be interrupted. A ventricular tap was performed followed by air injection and ventriculography. The tumour was later removed with success.

Of the 222 cases in which encephalography was $\square$ performed, 82 presented with choked disks. The patient's condition deteriorated in six cases only, $\stackrel{\bigcirc}{\Omega}$ in four of which papilloedema was present. One $\underset{\propto}{\mathbb{Q}}$ of these patients, the case of pinealoma, was in good 0 condition when the examination started, but the other five, including the two cases with no choked disks, were in poor condition. Some were rather drowsy, some had severe headache and stiffness of the neck. A ventricular tap improved the condition in three cases. In one case the examination must be considered to have contributed to the fatal outcome. Curiously enough in this case the encephalography was successful in so far as the gas entered the ventricular system and a blocking of the C.S.F. pathways was not therefore caused by the tumour.

\section{Discussion}

In discussing which method should be used, encephalography or ventriculography, some authors claim that encephalography should not be used if the degree of papilloedema exceeds 2 diopters. In

TABLE VI

TUMOURS IN CEREBELLUM OR FOURTH VENTRICLE

\begin{tabular}{|c|c|c|c|c|c|c|c|c|c|c|}
\hline \multirow{2}{*}{$\begin{array}{c}\text { Technique } \\
\text { Used }\end{array}$} & \multicolumn{2}{|c|}{ Positive } & \multicolumn{2}{|c|}{ Negative } & \multicolumn{2}{|c|}{ Tumour Suspected } & \multicolumn{2}{|c|}{$\begin{array}{c}\text { Incomplete } \\
\text { Air-filling }\end{array}$} & \multicolumn{2}{|c|}{$\begin{array}{l}\text { Air in Cisterns } \\
\text { Indicating Tumour }\end{array}$} \\
\hline & $\begin{array}{c}\text { Choked } \\
\text { Disks }\end{array}$ & $\begin{array}{c}\text { No } \\
\text { Choked } \\
\text { Disks }\end{array}$ & $\begin{array}{l}\text { Choked } \\
\text { Disks }\end{array}$ & $\begin{array}{c}\text { No } \\
\text { Choked } \\
\text { Disks }\end{array}$ & $\begin{array}{c}\text { Choked } \\
\text { Disks }\end{array}$ & $\begin{array}{c}\text { No } \\
\text { Choked } \\
\text { Disks }\end{array}$ & $\begin{array}{l}\text { Choked } \\
\text { Disks }\end{array}$ & $\begin{array}{c}\text { No } \\
\text { Choked } \\
\text { Disks }\end{array}$ & $\begin{array}{l}\text { Choked } \\
\text { Disks }\end{array}$ & $\begin{array}{c}\text { No } \\
\text { Choked } \\
\text { Disks }\end{array}$ \\
\hline $\begin{array}{l}\text { Encephalography } \\
\text { Ventriculography }\end{array}$ & $\begin{array}{r}3 \\
23\end{array}$ & $\overline{3}$ & - & - & - & - & 23 & 6 & $\underline{5}$ & 1 \\
\hline
\end{tabular}


our material this occurred in 35 cases and in only four the encephalogram was not tolerated, but this was also the case in two patients with no papilloedema.

In our opinion a comparison between complications following encephalography and ventriculography must inevitably be difficult. It is almost impossible to get two series of cases which from a clinical point of view are equal enough to permit a fair comparison. When a ventriculogram has been performed the operation is done the same day if the lesion is considered operable. A post-operative death under such circumstances cannot as a rule be attributed to the preceding examination. In 11 cases where ventriculography had demonstrated inoperable lesions death occurred in one only, and even in this case-a glioma of the pons-the death could not be ascribed to the examination but was a result of a progression of the advanced symptoms of the inoperable lesion.

In dealing with intracranial expanding lesions, everybody will agree that it is of the greatest importance for the surgeon to have as complete information as possible concerning the nature and the extent of the lesion. Cerebral pneumography and angiography are methods which in this respect are generally the most reliable. Sometimes angiography alone gives all the information wanted, sometimes pneumography. Not seldom both methods have to be tried before all the required information is obtained. The method first used depends of course on the clinical signs and symptoms. The general indications for pneumography stated earlier in this paper obey no definite rules, but are sometimes modified according to the state and condition of the patient. For example, in some cases of suspected angioreticuloma of the cerebellum the first examination has been vertebral angiography.

There is no doubt that encephalography is a more complete examination than ventriculography and from a technical point of view a smaller procedure. We know that ventriculography is not a harmless procedure and when there is a displacement of the ventricular system the puncture of the ventricles may be difficult and cause severe damage to the brain. That is why in this series of cases encephalography was tried as a first procedure in practically every case where an air study had been considered to be indicated.

In our opinion a grouping of the tumours is necessary to allow more reliable conclusions to be drawn. Some of our groups are too small, and it is possible that in a bigger series the grouping might be more precise regarding the localization and nature of the tumour. However, we feel that from this series the following statements can be made:-

1. With the technique used and the precautions taken, the risks of encephalography in cases of brain tumour with increased intracranial pressure can practically be eliminated.

2. Of 205 cases of supratentorial brain tumour (suprasellar excluded), 101 presented with choked discs. Ventriculography had to be done in only 15 of these cases. Encephalography and angiography localized the tumour in the remaining cases.

3 . Of the 36 cerebellar tumours, 30 presented with choked discs. In 23 of these cases ventriculography had to be done; encephalography localized the tumour exactly in three. In another five cases the appearance of the cisterns localized the tumour in the correct hemisphere.

4. A study of the cisterns is of great value in differentiating between extra- and intra-pontine lesions and for the demonstration of pontine angle tumours too small to cause displacement of the ventricular system.

5. The answer to the question in the title of the paper should in our opinion be, with the technique used, encephalography can and should be performed in practically every case where an air study is indicated. Even in those cases where ventriculography is necessary for examination of the ventricular system, encephalography is often of great value and should be performed as a first procedure.

\section{REFERENCES}

David, M., Ruggiero, G., and Talairach, J. (1954). Acta radiol. (Stockh.), 42, 37 .

Dressler, W., and Albrecht, K. (1956). Z Zbl. Neurochir., 16, 85.

Falk, B. (19531). Acta radiol. (Stockh.), 35, 304.

(1953). Ibid., 40, 220.

Lindgren, E. (1949). Acta radiol. (Stockh.), 31, 161. (1950). Ibid., 34, 331 .

(1951). "Pneumographie des Schädels". In Lehrbuch der $R$ öntgendiagnostik, 5th ed. Edited by Schinz, H. R., Baensch, W. E., Friedl, E., and Uehlinger, E. Thieme, Stuttgart.

(1954). Handbuch der Neruochirurgie, Vol. 2: Rontgenologie. Edited by Olivecrona, H., and Tönnis, W. Springer, Berlin.
Hogien.

Robertson, E. G. (1941). Encephalography. Macmillan, Melbourne. (1946). Further Studies in Encephalography. Macmillan, Melbourne.

Ruggiero, G. (1956). Acta radiol. (Stockh.), 46, 99.

Sheldon, P., Wickbom, I, and Pennybacker, J.' B. (1953). J. Fac. Radiol. (Lond.), 4, 275.

Wickbom, I., and Sheldon, P. (1953). Acta radiol. (Stockh.), 40, 249.

Zülch, K. J., Hirnödem, Hirnschwellung, and Hirndruck (1951). Zbi. Neurochir., 11, 350. 